\title{
Sistemas de Informação das Condicionalidades do Programa Bolsa Família
}

O presente Artigo tem por objetivo apresentar os sistemas responsáveis por operacionalizar e apoiar a gestão das condicionalidades do Programa Bolsa Família (PBF), gerido pela Secretaria Nacional de Renda de Cidadania (SENARC) do Ministério de Desenvolvimento Social e Combate à Fome (MDS), sob a perspectiva de monitoramento e avaliação desse processo. Para tanto, o artigo apresenta em breves descrições as principais características e funcionalidades de cada um dos Sistemas.

\section{Contextualização}

As condicionalidades do Programa Bolsa Família devem ser entendidas como um compromisso de dois lados: o poder público e as famílias. Se, por um lado, estas últimas devem cumprir uma agenda mínima relacionada às políticas de saúde e educação, por outro, aumenta a responsabilidade do poder público em prover serviços nessas áreaš ${ }^{4}$. A expectativa em relação às condicionalidades, explicitada na legislação e nos documentos oficiais do Programa, é de que seu acompanhamento tanto possibilite o acesso e a inserção da população pobre nos serviços sociais básicos de saúde e educação, como favoreça a interrupção do ciclo de reprodução da pobreza ${ }^{5}$. À medida que as crianças e adolescentes aumentam os anos de escolaridade e têm melhores condições de saúde e nutrição, tornam-se mais capacitados e com melhores condições de desenvolvimento físico e intelectual, fatores que contribuem para o desenvolvimento humano.

As condicionalidades do PBF incluem, na área de educação, a matrícula, pelas famílias beneficiárias, das crianças e adolescentes na escola, com a manutenção da frequência mínima mensal de $85 \%$ para os estudantes com idade entre 6 e 15 anos e de $75 \%$ para os de 16 e 17 anos. No caso da saúde, as famílias com crian- 
ças menores de sete anos devem periodicamente levar seus filhos ao serviço de saúde, ou receber visitas das equipes de saúde da família, para o monitoramento do crescimento e desenvolvimento da criança, bem como do calendário de vacinas, e as gestantes devem realizar o acompanhamento do pré-natal e participar de atividades educativas sobre aleitamento materno e alimentação saudável.

A periodicidade do acompanhamento das condicionalidades na saúde e educação é distinta. Enquanto que na educação o acompanhamento é bimestral (realizado cinco vezes ao ano), na saúde é realizado a cada seis meses.

Desde sua implementação, as condicionalidades do PBF nas áreas de saúde e educação ganharam escala, abrangência territorial ${ }^{6}$ e maior refinamento nos dados coletados. Tal fato gerou a necessidade de se criar e aperfeiçoar sistemas de informação com instrumentos para o monitoramento de processos e resultados, viabilizando assim a operacionalização e a gestão, de maneira a alcançar os objetivos das condicionalidades. Esses sistemas são o Sicon - Sistema de Condicionalidades e os respectivos sistemas criados pelos $\mathrm{Mi}$ nistérios da Saúde e da Educação para o acompanhamento das condicionalidades nessas áreas - Sistema de Gestão do Programa Bolsa Família na Saúde e Sistema Presença.

Esses sistemas viabilizam a operacionalização de ações que estão no núcleo do processo de gestão das condicionalidades $^{7}$ do Programa Bolsa Família: a) geração e disponibilização do público para acompanhamento das condicionalidades; b) a coleta e o registro das informações nos sistemas informatizados do Ministério da Saúde e Educação; c) identificação das famílias com integrantes em descumprimento de condicionalidades, e se for o caso, a aplicação de efeitos de condicionalidades ${ }^{8}$;) a análise dos resultados do acompanhamento, especialmente os relacionados às famílias em descumprimento que podem estar em situação de vulnerabilidade ou risco social.

\footnotetext{
4 Cunha, 2009.

5 Senna et al, 2007.

6 Atualmente há acompanhamento das condicionalidades em todos os 5.570 municípios brasileiros.

7 Referente ao artigo $1^{\circ}$ da Portaria MDS n² 251/2012.

8 São desdobramentos que podem afetar os benefícios das famílias em virtude do não cumprimento das condicionalidades. Atualmente existem quatro efeitos: advertência, bloqueio, suspensão e cancelamento do benefício.
}

Revista Brasileira de Monitoramento e Avaliação | Número 6 | Julho-Dezembro de 2013 
Trataremos nas próximas seções do papel desempenhado pelos Sistemas Sicon, Presença/MEC e Bolsa Família na Saúde/MS no processo de gestão das condicionalidades.

\section{Sistema de}

\section{Condicionalidades} do Programa Bolsa Família (Sicon)

O Sicon é a ferramenta elaborada pelo MDS para operacionalizar a gestão de condicionalidades do Programa Bolsa Família (PBF). Tal recurso apoia e referencia a promoção da gestão intersetorial nas três esferas de governo, característica essencial para que o Programa atinja seus objetivos centrais - alívio imediato da pobreza, ruptura do ciclo de reprodução da pobreza entre gerações e promoção do acesso aos serviços sociais básicos de saúde, educação e assistência social.

Trata-se de um sistema multiusuário para gestores e técnicos federais, estaduais e municipais e Instâncias de Controle Social (ICS). O Sicon possui seis funções distintas que garantem a efetivação da gestão das condicionalidades:

1. Identificar os beneficiários do PBF com perfil condicionalidades e gerar o público a ser acompanhado pelos Ministérios da Educação e da Saúde;

2. Consolidar as informações do acompanhamento realizado pelos $\mathrm{Mi}$ nistérios da Educação e da Saúde, identificando as famílias com beneficiários que não conseguiram cumprir os compromissos e procedendo às respectivas repercussões no benefício das famílias;

3. Integrar as informações do Cadastro Único, do histórico de pagamento e composição dos benefícios, de frequência escolar e do acompanhamento da agenda de saúde, possibilitando um diagnóstico mais acurado do contexto familiar no âmbito do Programa;

4. Informar e orientar acerca da importância do acesso aos serviços básicos de educação e saúde por meio da geração de notificações ${ }^{9}$.

5. Apoiar a integração de Serviços, Benefícios e Transferências de Renda no âmbito do Sistema Único de Assistência Social ao disponibilizar funcionalidades que protegem o benefício das famílias (Recurso Online ${ }^{10}$ e Interrupção Temporária ${ }^{11}$ ) e que registram a oferta de serviços socioassistenciais às famílias do Programa Bolsa Família (Módulo de Acompanhamento Familiar);

6. Disponibilizar relatórios sintéticos relativos aos processos que compõem a gestão das condicionalidades e norteiam a tomada de decisão.

Dessa forma, o Sicon se estabelece como instrumento de gestão que identifica, sistematiza e traz visibilidade a situações relacionadas à inadequação na oferta e acesso aos serviços sociais básicos e ligadas também às vulnerabilidades vivenciadas pelas famílias beneficiárias, credenciando-se como um sistema de monitoramento e avaliação de resultado das condicionalidades do Programa Bolsa Família. 
O Sistema, que hoje detém múltiplas funcionalidades, nasceu em 2006 com a tarefa de gerar, sistematicamente, os Públicos para Acompanhamento das Condicionalidades de Educação e Saúde - até então produzidos pela Caixa Econômica Federal - e começou a realizar o processo de Repercussão ${ }^{12}$. Ressalta-se que esses processos foram executados de forma não automatizada até o final de 2007.

Em 2008, o Sicon foi apresentado na estrutura de aplicação web. Essa versão era conhecida como "Sicon - Módulo de Recursos", e possuía apenas a funcionalidade de registrar as contestações das famílias que foram registradas como em descumprimento de condicionalidades. Esta versão constituiu o primeiro contato que os técnicos do PBF tiveram com esse Sistema.

O Sicon, em 2009, tornou-se mais robusto com a adição de novas funcionalidades - relatório analítico das famílias que descumpriram as condicionalidades e os relatórios consolidados que apresentam os resultados de acompanhamento das condicionalidades de Educação e Saúde. Deste modo, o Sistema habilitou-se como uma ferramenta do cotidiano de gestores e técnicos municipais do programa Bolsa Família e, a partir de então, inúmeras funcionalidades foram adicionadas ao Sistema, destacando-se:

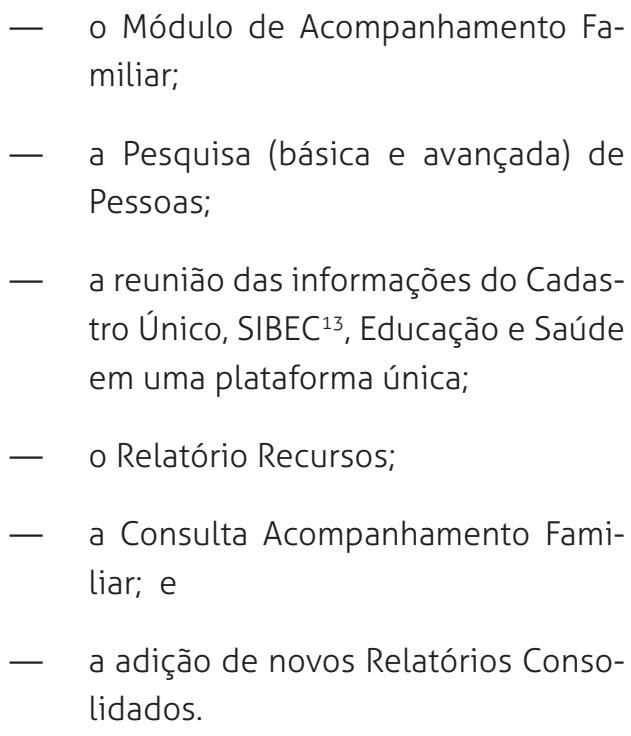

9 São correspondências impressas e entregues, pelos Correios, diretamente às famílias que descumpriram as condicionalidades.

10 Ferramenta criada para registrar e julgar as contestações apresentadas pelas famílias em decorrência do descumprimento de condicionalidades.

11 Funcionalidade disponível no Módulo de Acompanhamento Familiar que permite "proteger" o benefício da família em virtude do descumprimento de condicionalidade.

12 É o processo de consolidação dos resultados das condicionalidades, identificação dos beneficiários que deixaram de cumprir os compromissos assumidos e a aplicação dos efeitos de condicionalidades para as famílias em situação de descumprimento.

13 Sistema de Benefícios ao Cidadão da Caixa Econômica Federal.

Revista Brasileira de Monitoramento e Avaliação | Número 6 | Julho-Dezembro de 2013 
Sob a perspectiva de monitoramento, o Sicon identifica as famílias que possuem dificuldades no acesso aos serviços básicos de Saúde e Educação. Com a Pesquisa Avançada de Descumprimento, é possível gerar uma consulta analítica que lista todas as famílias que descumpriram as condicionalidades por território, tipo de benefício ${ }^{14}$, tipo de efeito ${ }^{15}$ e mês de repercussão. As Figuras I, II e III ilustram a Pesquisa.

\section{- figura 1: PESOUUISA AVANÇAdA dE DESCUMPRIMENTO - SELEÇÃo DOS FILTROS DA PESOUISA}

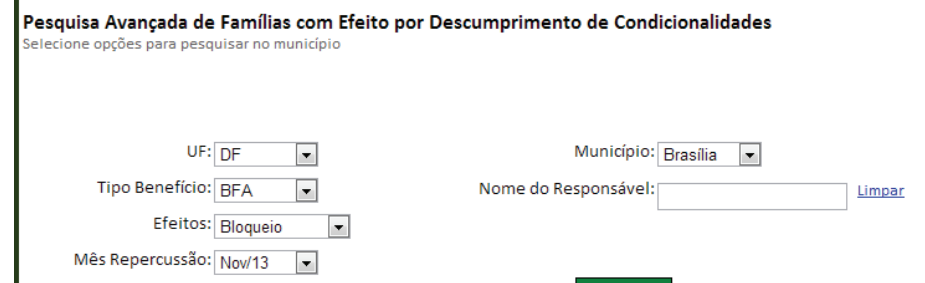

FIGURA 2: PESOQUISA AVANÇADA DE DESCUMPRIMENTO - RESULTADO DA PESOUUISA EM TELA

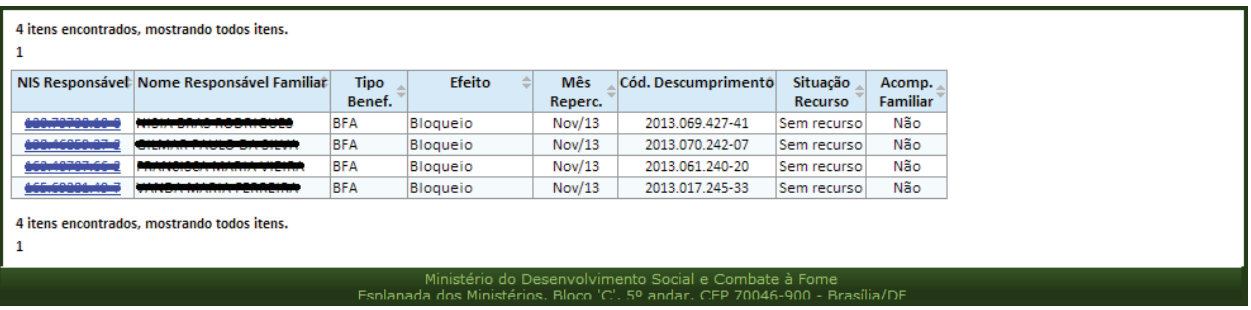

Fonte: Painel de indicadores de condicionalidades (DECON/MDS)

FIGURA 3: PESOUUISA AVANÇADA DE DESCUMPRIMENTO - GERAR O RELATÓRIO EM CSV, EXCEL E PDF

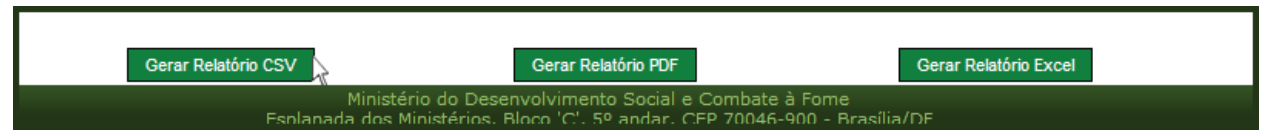

Fonte: Painel de indicadores de condicionalidades (DECON/MDS) 
- Figura 4: PESOQUisa básica de PESSOA - ABA FAMÍlia

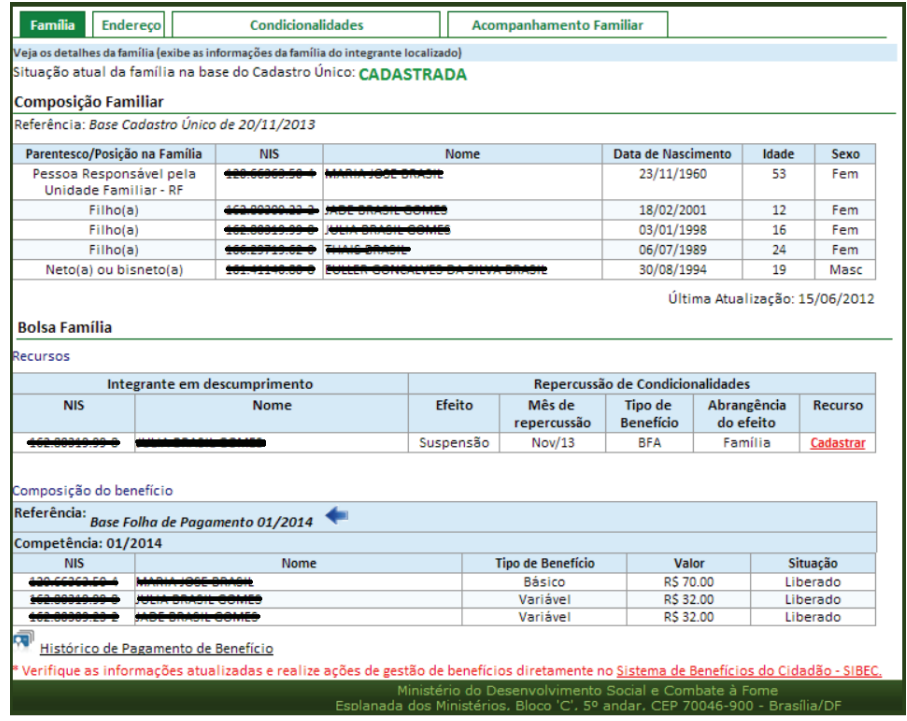

Fonte: Painel de indicadores de condicionalidades (DECON/MDS)

- figura 5: PESOQuisa básica de PESSOA - ABA família

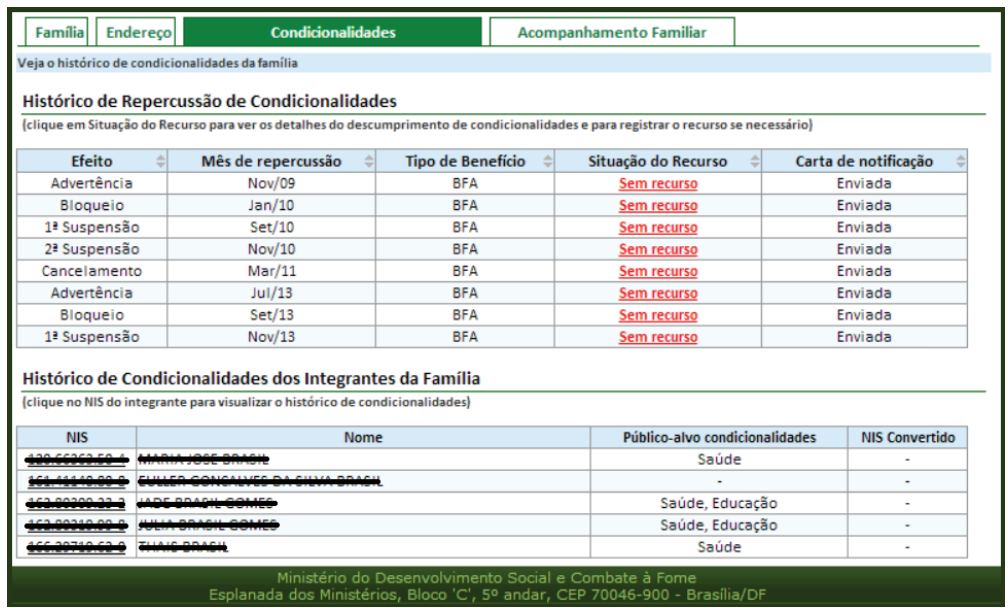

Fonte: Painel de indicadores de condicionalidades (DECON/MDS)

14 BFA - Benefício da Família e BV] - Benefício variável vinculado ao adolescente.

15 Atualmente existem quatro tipos de efeito: advertência, bloqueio, suspensão e cancelamento.

Revista Brasileira de Monitoramento e Avaliação | Número 6 | Julho-Dezembro de 2013 
Na Pesquisa Básica de Pessoa do Sicon,

A Figura V - apresenta a aba "Condicionaao consultar o Número de Identificação Social (NIS) de um beneficiário do Bolsa Família, o Sistema apresenta as principais informações do grupo familiar sob diferentes perspectivas, integrando e reunindo dados de diversos sistemas - Cadastro Único, SIBEC, Sistema Presença, Bolsa Família na Saúde - em uma plataforma única de consulta, possibilitando uma avaliação $\because$ mais precisa de contexto daquela família.

A Figura IV - apresenta a aba "Família" - exibe informações da composição familiar, da composição do benefício e do histórico de pagamento, além disso, informa se a família possui recurso on-line a cadastrar.

lidades" - mostra o histórico de repercussão da família e a possibilidade de consulta ao histórico de acompanhamento das condicionalidades de Educação e Saúde.

O Sicon possui funcionalidades que subsidiam a avaliação de resultado. Sob esta perspectiva, destacam-se os Relatórios Consolidados, que possuem, atualmente, seis categorias que totalizam vinte tipos de relatórios e sintetizam os principais resultados das condicionalidades. Para isso, deve-se selecionar o Tipo de Relatório, o Período (inicial e final) e a Abrangência Territorial (Brasil, UF ou Município). As Figuras VI e VII ilustram a principal ferramenta de relatórios do Sicon.

\section{- FiguRA 6: RELATÓRIOS CONSOLIDADOS - SELEÇÃO DE RELATÓRIOS}

\begin{tabular}{|l|l|}
\hline "Tipo Relatório & \\
(Selecione o Tipo de relatório) & Repercussão \\
Saúde & Repercussões - BFA \\
Acompanhamento Saúde - Familias & Repercussões - BV \\
Acompanhamento Saúde - Crianças & Recursos \\
Acompanhamento Saúde - Resultados para IGD & Recursos - BFA \\
Educação & Recursos - BV J \\
Acompanhamento Educação - Frequência Escolar de Beneficiários de 6 a 15 anos & Motivos dos Recursos - BFA \\
Acompanhamento Educação - Frequência Escolar de Jovens do BVJ & Motivos dos Recursos - BV J \\
Acompanhamento Educação - Motivos da baixa Frequência BFA e BV & Acompanhamento Familiar \\
Acompanhamento Educação - Resultados para IGD & Acompanhamento Familiar \\
Acompanhamento Educação - Resultados das Escolas Estaduais & Acompanhamento Familiar - Resultado para IGD \\
Em Fase de Suspensão & \\
Familias e/ou jovens em fase de suspensão & \\
\hline
\end{tabular}

Fonte: Painel de indicadores de condicionalidades (DECON/MDS) 
FIGURA 7: RELATÓRIOS CONSOLIDADOS - SELEÇÃO
DE FILTROS E TIPO DE AROQUIVO (EXCEL, CSV OU PDF).

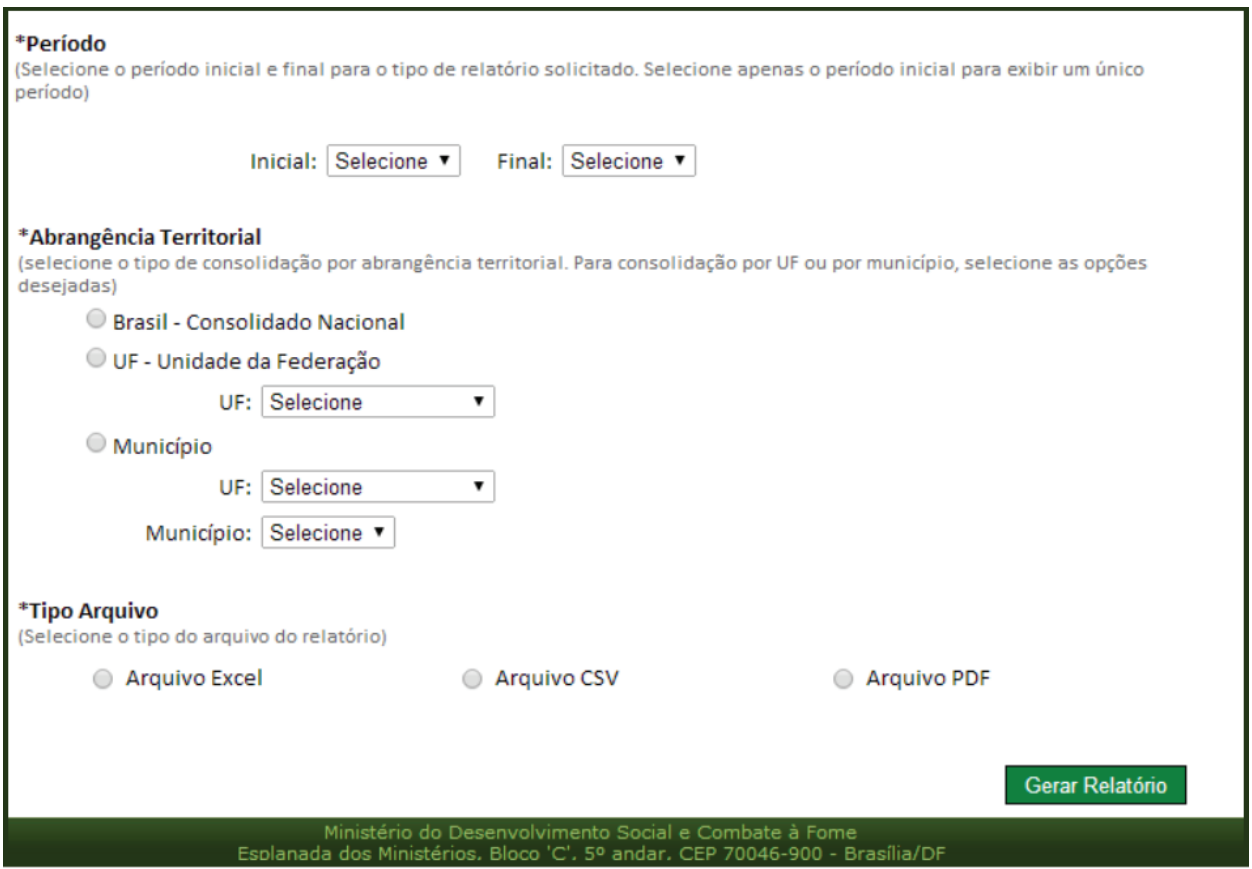

Fonte: Painel de indicadores de condicionalidades (DECON/MDS)

O Sicon dispõe de outras funcionalidades capazes de apoiar e fomentar ações de monitoramento e avaliação nas três esferas de governo, possibilitando o constante aprimoramento dos processos que compõem a gestão de condicionalidades do PBF. Ressalta-se a importância dos sistemas desenvolvidos pelo MEC e MS para a consolidação do Sistema de Condicionalidades do Programa Bolsa Família.
III. O Sistema Presença no monitoramento da frequência escolar dos beneficiários do Programa Bolsa família

O acompanhamento da frequência escolar tem se mostrado uma ação fundamental no Programa Bolsa Família para o objetivo de romper o ciclo de pobreza entre 
gerações. Com essa ação, a assiduidade, a permanência e o rendimento escolar das crianças e adolescente integrantes de famílias beneficiárias apresentam melhorias que contribuem para a formação de uma geração mais escolarizada e capacitada para a superação da condição de pobreza em que se encontram.

Para o êxito e a manutenção do trabalho de acompanhamento da frequência escolar, o Sistema Presença de Acompanhamento da Frequência Escolar do Programa Bolsa Família (Sistema Presença), criado e mantido pelo Ministério da Educação, é um instrumento de primeira importância. Ele possibilita a capilaridade na atuação da rede de acompanhamento da frequência escolar, a resposta tempestiva às demandas por informação e favorece a boa gestão do processo de acompanhamento realizado a cada bimestre.

Criado em 2006 - numa ação coordenada pela Secretaria de Educação Continuada, Alfabetização, Diversidade e Inclusão SECADI-MEC - o Sistema Presença substituiu o sistema emergencial da Caixa Econômica Federal para acompanhamento da frequência escolar dos beneficiários do Programa Bolsa Família.

\section{O ACOMPANHAMENTO DA SITUAÇÃO ESCOLAR DOS BENEFICIÁRIOS}

O acompanhamento da condicionalidade da educação, realizado bimestralmente, envolve um público de mais de $17 \mathrm{mi}$ lhões de crianças e adolescentes na faixa etária de 6 a 17 anos. No último acompanhamento feito, referente à frequência escolar de outubro e novembro de 2013. eram 17,4 milhões de crianças e adolescentes no público para acompanhamento da condicionalidade da educação.

A maioria do público é acompanhada a cada bimestre em índices crescentes desde o início da operação do Sistema Presença em 2006. Conforme pode ser observado no gráfico 1 , no acompanhamento referente a outubro e novembro de $2013,92,2 \%$ foram acompanhados, correspondendo a 16,1 milhões de estudantes.

A operação de acompanhamento, realizada cinco vezes ao ano, mobiliza diretamente para registro da frequência escolar aproximadamente 40 mil profissionais, além da rede de trabalhadores das escolas encarregados de coletar a frequência junto aos diários de classe e registrar o motivo de eventuais situações de assiduidade abaixo da mínima exigida no Programa. 


\section{- GRÁFICO 1: RELATÓRIOS CONSOLIDADOS - SELEÇÃO DE FILTROS E TIPO DE AROQUIVO (EXCEL, CSV OU PDF).}

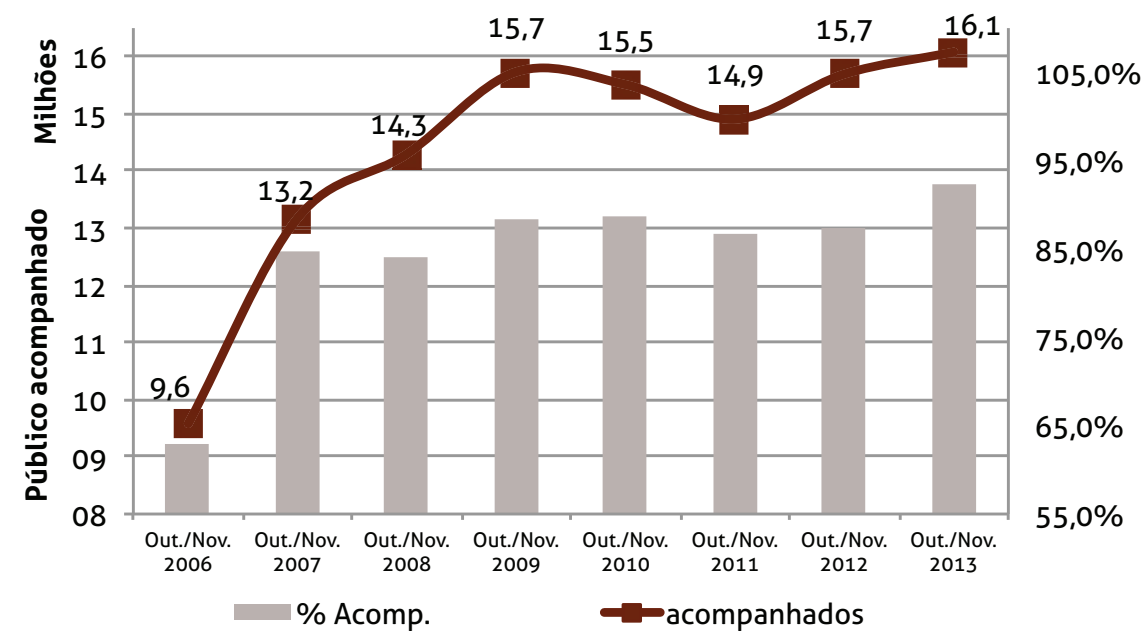

Fonte: Painel de indicadores de condicionalidades (DECON/MDS)

Desde sua criação em 2006, o Sistema Presença busca se ajustar às necessidades do usuário. Com isso, têm aprimorado as funcionalidades já existentes e criado outras, tornando-o mais adequado aos desafios inerentes ao trabalho do acompanhamento da frequência escolar.

As funcionalidades desse Sistema possibilitam desde o adequado cadastramento dos usuários em diferentes perfis de acesso até o monitoramento e a análise do processo de registro bimestral, com a impressão de relatórios gerenciais. Entre as funcionalidades disponibilizadas na plataforma web aos usuários do Sistema destacam-se:
- Impressão de formulários com a lista de estudantes por escola para coleta de dados;

- Transferência de alunos para atualização da escola em que estudam;

- Coleta e registro da frequência escolar dos estudantes;

- Relatório da série histórica frequência escolar por estudante;

- Relatório gerencial para monitoramento do acompanhamento, por escola ou por unidade territorial;

- Relatório de baixa frequência por estudante com a informação do motivo; 
- Relatório analítico dos beneficiários sem identificação de escola;

- Cadastramento de usuários;

- Relatório sobre operadores do Sistema;

- Quadro de aviso aos usuários;

- Manual do Sistema e outros documentos.

\section{A OPERAÇÃO DE ACOMPANHAMENTO}

Para a operacionalização do processo de acompanhamento da frequência escolar é necessária uma estreita articulação entre - Sicon (Sistema de Condicionalidades) e o Sistema Presença, pois cabe ao MDS (Ministério do Desenvolvimento Social e Combate a Fome) a geração do público de acompanhamento da condicionalidade da educação.

A identificação das escolas que integram as redes públicas e privadas do Brasil é carregada nas bases de dados do Cadastro Único, Sicon e Sistema Presença. Os dados das escolas são obtidos do Censo Educacional realizado anualmente pelo Instituto Nacional de Pesquisa Educacional Anísio Teixeira (INEP), e atualmente são 198 mil escolas ativas.

Na geração do público, o Sicon obtém do Cadastro Único para Programas Sociais e da Folha de Pagamento do Programa Bolsa Família as informações para configuração do público, e as atualiza de forma incremental ${ }^{16}$ no Sistema Presença por meio de transmissão de arquivo com formatos e em prazos previamente acertados.
Com os dados atualizados a partir da troca de informações com o Sicon, o Sistema Presença disponibiliza aos municípios o público para acompanhamento com a informação da escola e o ano/série frequentado pelo beneficiário, entre outros dados que permitem a identificação do aluno e o conhecimento de sua situação escolar. A informação da escola e o ano/ série em que o beneficiário estuda são atualizadas no Sistema Presença, pois trata-se de informações dinâmicas, por isso muitas vezes alteradas num tempo inferior ao prazo legal exigido para atualização cadastral pelo Cadastro Único, isto é, dois anos.

O MEC, com sua rede de Coordenadores Estaduais e Coordenadores Municipais da Frequência Escolar e operadores do Sistema Presença, realiza o acompanhamento das condicionalidades com o registro individualizado da frequência escolar dos beneficiários integrantes do público. A operação é efetivada no âmbito dos municípios, sendo de responsabilidade da Secretaria Municipal da Educação. No acompanhamento,eé apurado se houve situação de frequência abaixo da exigida na condicionalidade da educação - 75\% para adolescente de 16 e 17 anos e 85\% para crianças de 6 a 15 anos. Nos casos em que há baixa frequência, registra-se o percentual obtido pelo beneficiário e o motivo da ausência às aulas. Situações de ausência de matrícula ou falta de oferta de aulas também são registradas no Sistema com seus respectivos motivos.

Conforme a circunstância que resultou na baixa frequência, ausência de oferta de aulas, haverá ou não efeitos no benefício 
da família. Há bloqueio, suspensão ou, excepcionalmente, cancelamento, somente nos casos em que a superação da situação registrada dependa predominantemente da atuação da família. Com o efeito no benefício, espera-se que a família mobilize-se e a situação seja superada.

\section{COLETA E REGISTRO DA FREQUÊENCIA ESCOLAR NO SISTEMA PRESENÇA}

As informações da frequência escolar são obtidas diretamente da escola por meio de formulários impressos do Sistema Presença ou pela inserção de dados no Sistema realizada pela escola. No acompanhamenta, as escolas que tenham capacidade técnica e operaciona, e desejem registrar diretamente a informação no Sistema Presença, podem se cadastrar, por meio do coordenador municipal do acompanhamento da frequência escolar no município.

A efetividade da rede estabelecida para coleta e registro da frequência escolar no Programa Bolsa Família, coordenada nacionalmente pelo Ministério da Educação, é fundamental para o sucesso do acompanhamento bimestral. Os municípios têm como gestorrdessa ação o Secretário Municipal da Educação. Este, por sua vez, designa o Coordenador Municipal da Frequência Escolar (o Operador Master Municipal).aEstr é o responsável direto pela manutenção do Sistema Presença no Município, e cadastramento dos demais usuários.da cidade.

- figura 8: Formulário para reGistro da freouênNCIA ESCOLAR

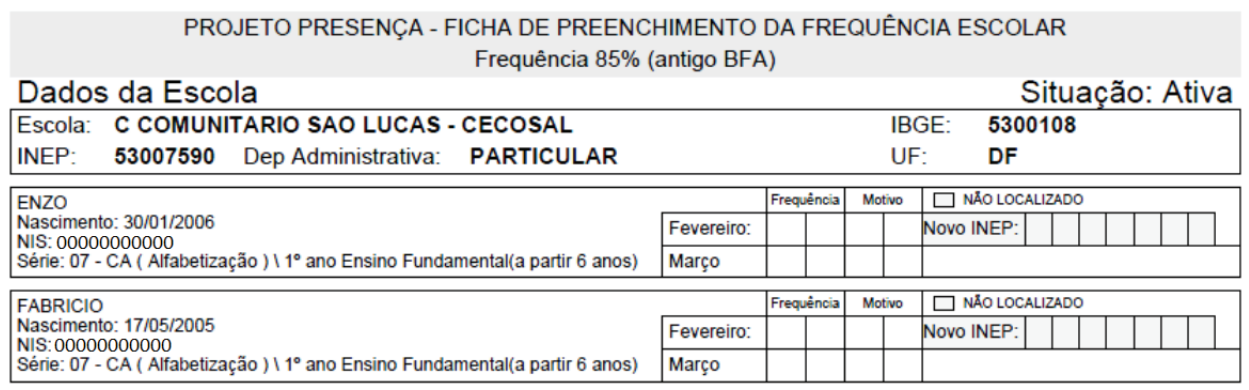

Fonte: Sistema Presença - MEC (fev./2014)

16 No processo incremental, o Sicon envia ao Sistema Presença os dados que foram alterados em relação aos que já estão carregados na base do Sistema Presença.

Revista Brasileira de Monitoramento e Avaliação | Número 6 | Julho-Dezembro de 2013 


\section{- FIGURA 9: SISTEMA PRESENÇA: TELA PARA REGISTRO DE DA FREOUÊNCIA ESCOLAR}

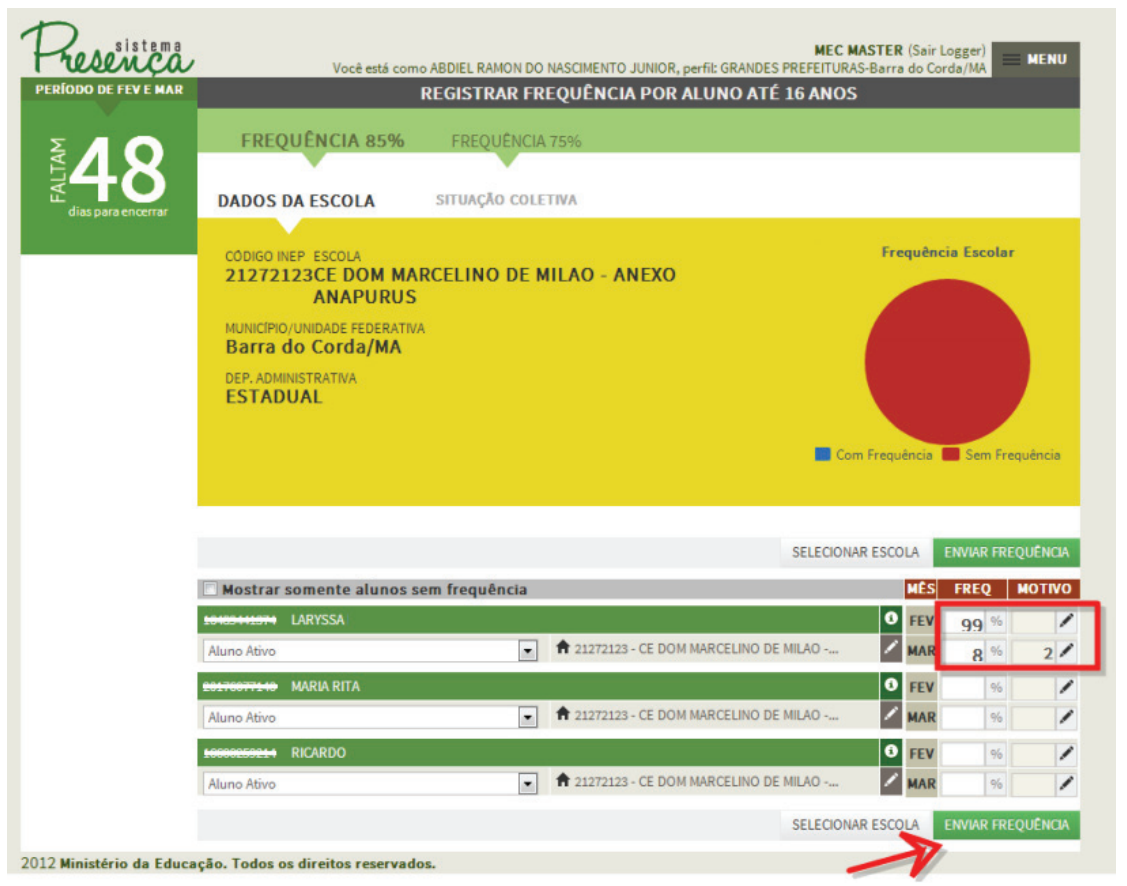

Fonte: Sistema Presença - MEC (fev./2014)

Na forma mais usual de coleta de dado, o Operador do Sistema Presença envia às escolas formulários com a lista nominal dos alunos beneficiários, conforme a figura VIII, para preenchimento das informações da frequência escolar do período. A escola retorna com o formulário preenchido registrando as baixas frequências apuradas e os respectivos motivos. Essas informações são inseridas no Sistema pelo Operador no prazo definido pelo calendário de acompanhamento.

Nesse processo, a escola preenche as informações de frequência e devolve ao operador municipal do sistema. Ao rece- ber os formulários preenchidos, o operador municipal faz o registro no Sistema. Para coleta e registro da informação, a coordenação municipal do acompanhamento da frequência dispõe deacerca de 40 dias, sendo os 10 dias iniciais, que correspondem aos dez últimos dias do bimestre a ser acompanhado, destinados à impressão e distribuição dos formulários nas escolas.

Nos casos em que o aluno já não se encontra na escola indicada no sistema, ele pode ser transferido para a nova escola em que estuda por meio da funcionalidade "transferência do aluno". Caso a nova 
escola seja desconhecida, o aluno ficará sem a identificação da escola, e disponível para ser alocado em uma nova unidade educacional se sua situação escolar for identificada. Por fim, caso o aluno estude em uma escola que não se apresente na tela do sistema - nessas situações se encontram em geral escolas que não participaram do Censo Educacional INEP do ano anterior -, ele será alocado na funcionalidade ESI (Escola Sem INEP) possibilitando assim o registro da frequência numa situação provisória até que a escola obtenha o código INEP.

Ao final de cada bimestre, os dados coletados são enviados ao Sicon, além de serem consolidados no próprio Sistema Presença. Com os dados carregadon, são verificadas os casos em que há descumprimento, sendo passíveis de advertência à família ou repercussão no benefício. A lista das famílias com registro de descumprimento, portanto em situação de vulnerabilidade,sé encaminhada para acompanhamento familiar na Assistência Social. Os dados consolidados do monitoramento ficam disponíveis, nas formas analítica e sintética, à rede de gestores e operadores, com a finalidade de realizar avaliações e estudos para a atuação na política pública.

\section{O Sistema de Gestão do PBF na saúde no monitoramento das condicionalidades de saúde dos beneficiários do Programa Bolsa família}

A agenda de condicionalidades de saúde do PBF propõe ações básicas de atenção à saúde, voltadas à infância e à gestação, que são fases críticas de cuidado, nas quais qualquer interferência negativa pode resultar em problemas importantes de saúde e nutrição para o resto da vida. Por isso, é importante monitorar essa agenda, e o Sistema de Gestão do Programa Bolsa Família na Saúde do Datasus ${ }^{17}$ é a ferramenta indispensável para tao. A figura $X$ apresenta a tela inicial do referido Sistema.

17 DATASUS é o nome do departamento de informática do Sistema Único de Saúde do Brasil. Trata-se de um órgão da Secretaria de Gestão Estratégica e Participativa do Ministério da Saúde com a responsabilidade de coletar, processar e disseminar informações sobre saúde.

Revista Brasileira de Monitoramento e Avaliação | Número 6 | Julho-Dezembro de 2013 


\section{- FIGURA 10: TELA INICIAL DO SISTEMA DE GESTÃO DO PROGRAMA BOLSA FAMÍLIA NA SAÚDE}

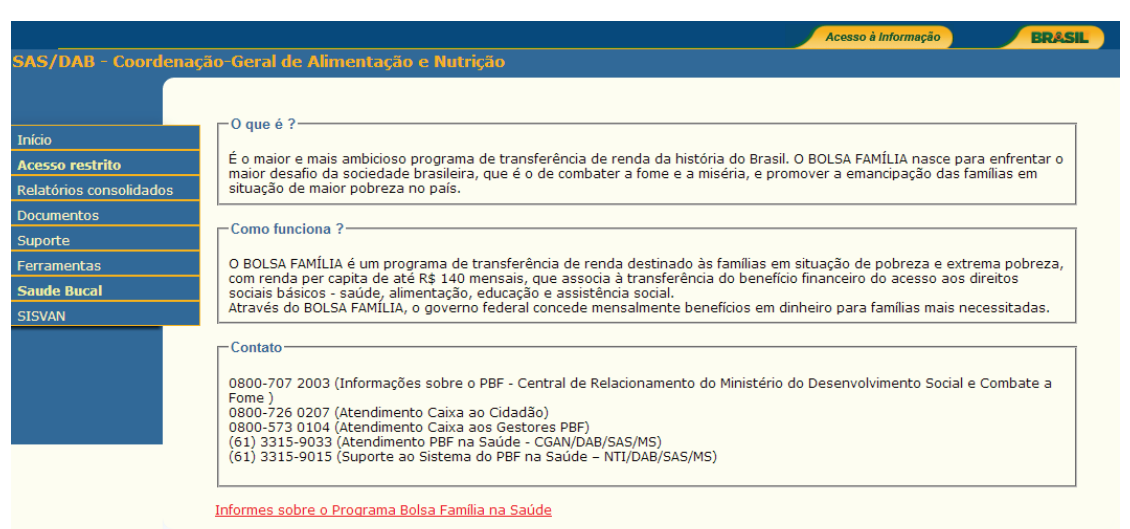

Fonte: Sistema de Gestão do Programa Bolsa Família na Saúde

Algumas funções desse Sistema da Saúde são de acesso público e outras somente são visualizadas pela coordenação municipal de saúde. Pelo acesso público podem ser gerados relatórios consolidados com resultados de acompanhamento de saúde das famílias beneficiárias, desagregados até o nível municipal com os seguintes indicadores: percentual de crianças e gestantes acompanhados pela saúde e, nesse universo, quantas crianças estavam ou não com a vacinação em dia e quantas gestantes cumpriram ou não a agenda de pré-natal, percentual de crianças e gestantes ainda não localizadas para o acompanhamento de saúde etc.
Na interface de acesso restrito (figura XI), a coordenação de saúde local visualizará outras funcionalidades do sistema essenciais para a gestão de condicionalidades e o monitoramento de processos e resultados do acompanhamento de saúde das famílias. Por exemplo, no que se refere à operacionalização das condicionalidades de saúde, o município, por meio da funcionalidade: "mapas de acompanhamento", poderá gerar a relação nominal, com o respectivo número de identificação social - NIS, dos integrantes das famílias beneficiárias do PBF que deverão ser acompanhados pela rede de atenção básica de saúde (figura XII). 
- FIGURA 11: TELA OUE APRESENTA DADOS GERENCIAIS DO ACOMPANHAMENTO DE SAÚDE

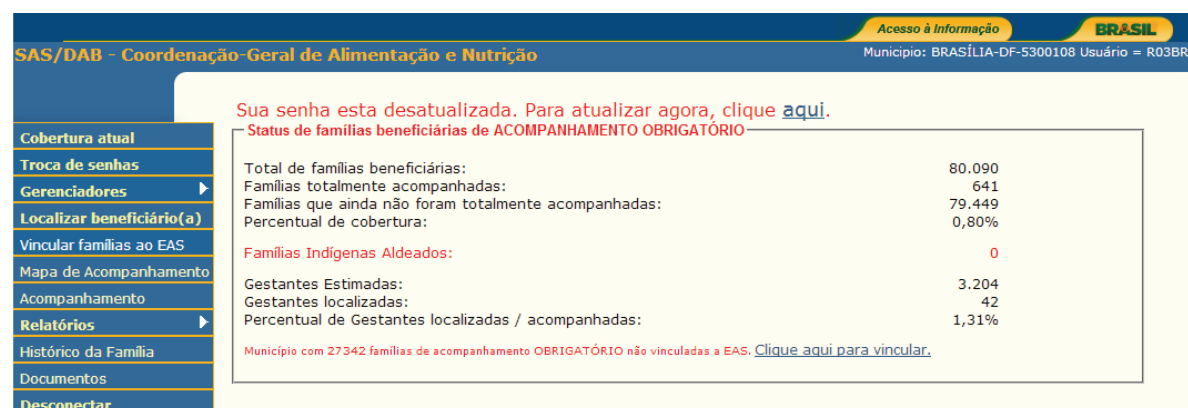

Fonte: Sistema de Gestão do Programa Bolsa Família na Saúde

- FIGURA 12: MAPA DE ACOMPANHAMENTO DAS CONDICIONALIDADES DE SAÚDE

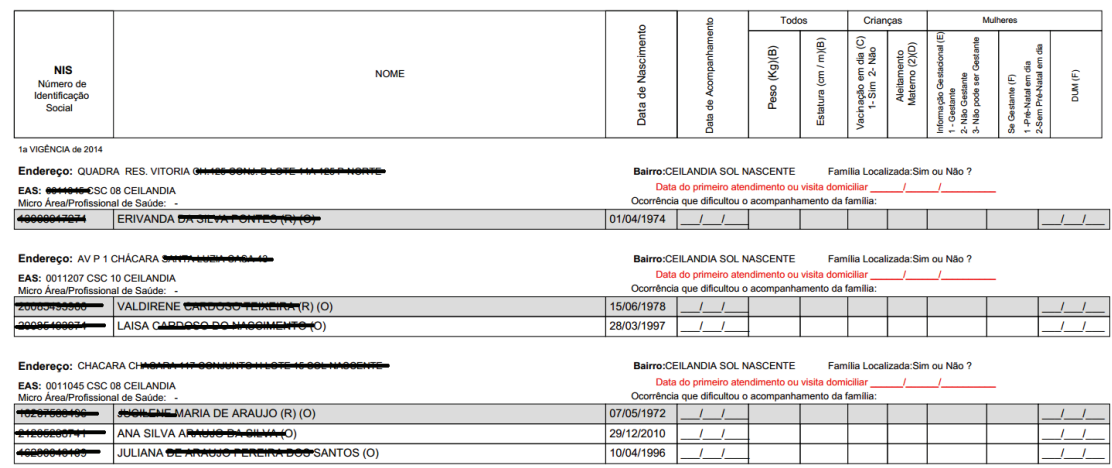

Fonte: Sistema de Gestão do Programa Bolsa Família na Saúde 
As informações coletadas e registradas nesses mapas, pela rede de atenção básica, para cada um dos integrantes da família no perfil saúde, são: data de nascimento e de acompanhamento; dados antropométricos para avaliação nutricional (peso e altura); dados sobre cumprimento ou não do calendário de vacinação preconizado pelo Ministério da Saúde (MS); informações sobre aleitamento materno; U informações sobre gestação (se está ou não gestante, ou se não pode ser gestante por ter passado por algum procedimento ginecológico e o cumprimento ou não do pré-natal das gestantes, além da data da última menstruação - DUM) (Figura XII).

Os mapas de acompanhamento podem ser impressos pela gestão municipal de saúde obedecendo a diferentes lógicas de territorialização dos serviços de saúde da atenção básica de cada município, por exemplo: a) impressão de mapas com a relação de famílias beneficiárias por seu vínculo de endereço/bairro; b) por vínculo à determinado estabelecimento de atenção à saúde c) ou mapa de famílias não vinculadas à nenhum estabelecimento de saúde, d) impressão de mapa constando apenas indígenas aldeados etc. Os mapas também podem ser impres- sos tendo por base estratégias de gestão para melhorar o acompanhamento das famílias, como a impressão de mapas por bairro das famílias que ainda não foram localizadas pelas equipes de saúde para o acompanhamento,apela marcação do filtro "não localizadas"

Portanto, o sistema tem sido aperfeiçoado no sentido de facilitar a identificação e o acompanhamento das famílias beneficiários do PBF, o que oportuniza o cumprimento de uma das premissas da política de atenção básic, qual seja, melhorar a identificação de famílias pobres para serem acompanhadas pela saúde, pois sãosgrupos familiares que podem estar em situação de maior vulnerabilidade e mais susceptíveis aos determinantes sociais de saúde, de maneira a ampliar seu acesso aos serviços de saúde.

No que se refere ao monitoramento de processos e resultados, por meio da funcionalidade Histórico da família (figura XIII) é possível observar, por integrante, informações importantes sobre sua situação de saúde e nutrição, como o cumprimento ou não do calendário de vacinação, do pré-natal, informações sobre peso e altura que possibilitam diagnósticos nutricionais ${ }^{18}$. 


\section{- FIGURA 13: TELA DE HISTÓRICO DOS RESULTADOS INDIVIDUAIS DO ACOMPANHAMENTO DA SAÚDE}

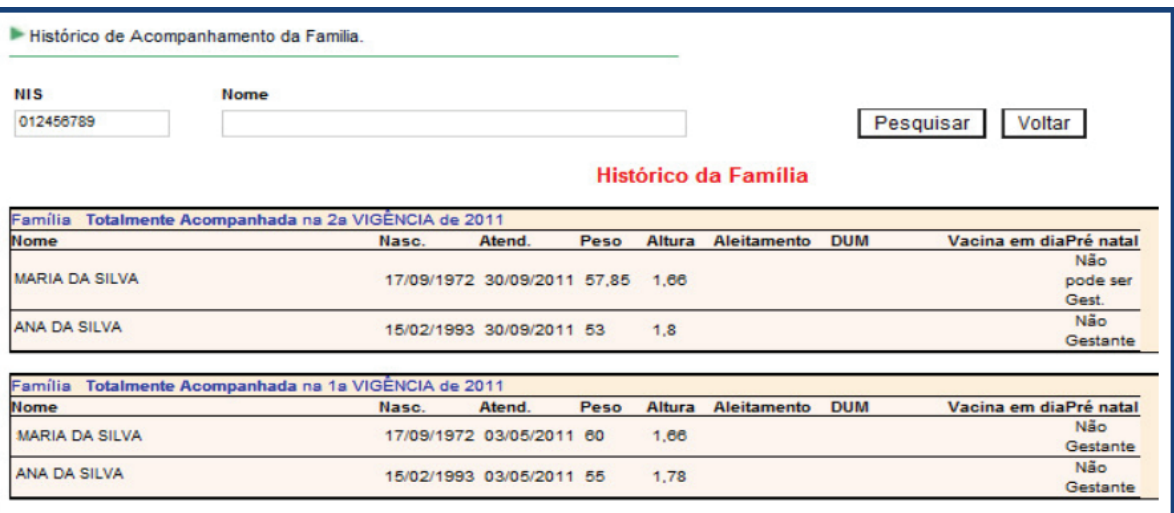

Fonte: Sistema de Gestão do Programa Bolsa Família na Saúde

Outro tipo de relatório disponibilizado pelo Sistema da Saúd, que permite à gestão municipal de saúde ter um retrato da situação das crianças e gestantes de sua região, é o relatório de descumprimento analítico, o qual apresenta os dados de descumprimento do calendário de vacinação ou do pré-natal, por integrante da família.

Dentre as novas funcionalidades do Sistema de Gestão do Programa Bolsa Família criadas para melhorar a identificação das famílias e o resultado do acompanhamento, podem ser citadas: 1) identificação das famílias indígenas aldeadas, 2) localização do beneficiário, não só pelo NIS; mas tam- bém pelo nome, data de nascimento ou número do Cartão Nacional de Saúde, 3) atualização do endereço da família, sendo que as duas últimas funcionalidades são bastante úteis no caso de famílias que mudaram de município e não atualizaram os dados no Cadastro único.

Em resumo, o Sistema de Gestão do Programa Bolsa Família na saúde permite aos responsáveis pela gestão das condicionalidades de saúde:

- imprimir mapas constando a relação das famílias beneficiárias a serem acompanhadas;

18 Os dados consolidados do estado nutricional das crianças e mulheres acompanhadas na saúde, ao final do período de acompanhamento, migram do Sistema de Gestão do PBF na Saúde para outro Sistema do Datasus - Sistema de Vigilância Alimentar e Nutricional - SISVAN - WEB

Revista Brasileira de Monitoramento e Avaliação | Número 6 | Julho-Dezembro de 2013 
- registrar os resultados do acompanhamento das condicionalidades de saúde;

- atualizar o endereço das famílias;

- vincular a família beneficiária à equipe de saúde que realizou o acompanhamento;

- visualizar o histórico de acompanhamento da família;

- visualizar as famílias em descumprimento de condicionalidades da saúde para busca ativa;

- gerar relatórios consolidados com os resultados parciais do acompanhamento das condicionalidades de saúde por município.

\section{O PÚBLICO DE}

\section{ACOMPANHAMENTO DAS}

\section{CONDICIONALIDADES DE SAÚDE}

\section{E A REDE DE ATENÇÃO BÁSICA}

\section{ENVOLVIDA NESSE PROCESS}

De acordo com dados do último período de acompanhamento de saúde $\left(2^{\circ}\right.$ semestre de 2013), foi alcançada uma cobertura de $73,44 \%$, o que equivale a mais de 8,6 milhões de famílias. O gráfico I mostra a evolução da cobertura de acompanhamento de saúde desde que essa ação foiaposta em prática. Pelos resultados, é possível afirmar que, a partir do segundo semestre de 2006, houve um aumento de mais de 40 pontos percentuais, e esse fato é um indicador de melhoria do acesso aos serviços de saúde pelas famílias em situação de maior vulnerabilidade social, além de aprimoramento no registro das informações de saúde prestadas.

A cada período de acompanhamento das condicionalidades de saúde, o MS recebe do MDS as famílias beneficiárias do PBF, cujos integrantes têm perfil para monitoramento da agenda de saúde (crianças menores de 7 anos e mulheres beneficiárias, para identificação de gravidez). No $2^{a}$ semestre de 2013, mais de 11,8 milhões de famílias formaram o público de acompanhamento das condicionalidades de saúde. Esse público é gerado com base nos dados do Cadastro Único e na folha de pagamento do PBF pelo Sicon, e é disponibilizado no Sistema de Gestão do Programa Bolsa Família para os municípios, de maneira que a rede de atenção básica local possa identificá-lo. Portanto, a operacionalização das condicionalidades ${ }^{19}$ de saúde envolve a rede de proteção básica municipal que se organiza para realizar o monitoramento dessa ação. Cabe às Secretarias Municipais de Saúde a indicação de um coordenador da saúde para acompanhar os processos de inserção e atualização das informações que resultam do acompanhamento no Sistema da Saúde. 0 fluxo operacional para o acompanhamento de saúde das famílias em geral envolve o preenchimento prévi, dos dados de saúde coletados, por pessoa, no mapa de acompanhamento citado. Mas esses dados também podem ser inseridos diretamente no Sistema de Gestão do PBF na Saúde, pois as mesmas informações do mapa constam no referido sistema. 


\section{- GRÁFICO 2: TELA DE HISTÓRICO DOS RESULTADOS INDIVIDUAIS DO ACOMPANHAMENTO DA SAÚDE}

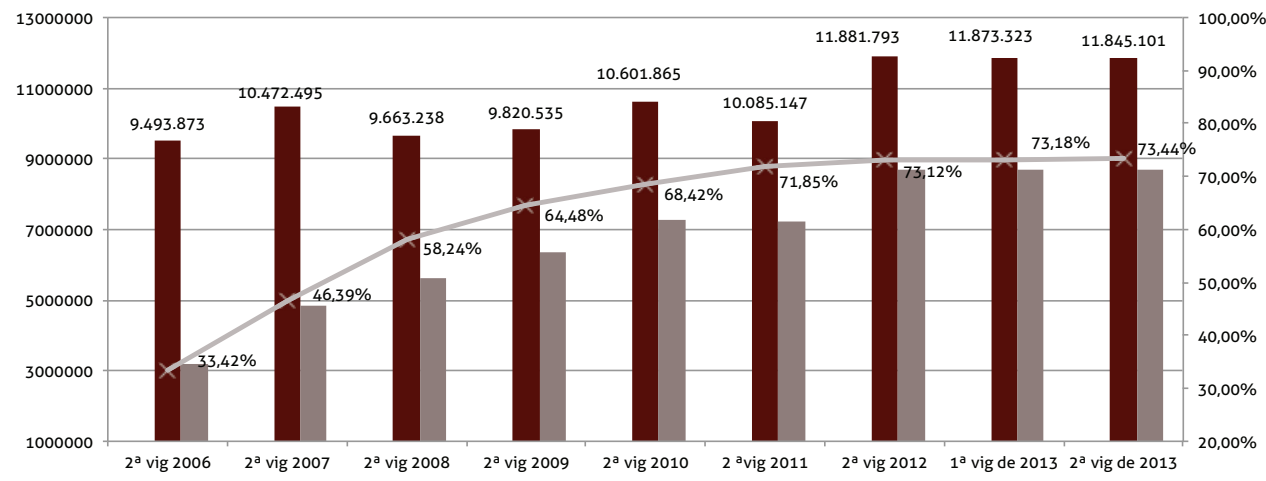

Fonte: Sistema de Gestão do Programa Bolsa Família na Saúde - Datasus/Dsb/MS. Elaboração: Coordenação - Geral de Acompanhamento das Condicionalidades/Senarc/MDS.

As ações previstas na agenda das condicionalidades de saúde são acompanhadas pelos profissionais dessa área presentes nas Unidades Básicas de Saúde, ou a família também podeereceber visitas daqueles que compõem as equipes da estratégia saúde da família (ESF). Esses atores formam uma grande rede de atuação da atenção básica, pois, segundo dados de 2013 do Departamento de Atenção Básica do MS, são mais de 250 mil agentes comunitários de saúdesem atividade, e 5.346 municípios com 34.715 equipes de saúde da famílis, além do fato de que em cada um dos 5.570 municípios há um coordenador municipal, designado pela Secreta- ria Municipal de Saúde, responsável pelo acompanhamento de saúde.

\section{Considerações finais}

Os principais objetivos do PBF são o combate à fome e à miséria e o rompimento do ciclo de reprodução da pobreza entre gerações. Dessa forma, aliada à transferência de renda, a gestão das condicionalidades articula ações que desempenham um papel fundamental para o alcance desses objetivos, ao reforçar o acesso dos beneficiários do Programa aos serviços sociais básicos de Educação e de Saúde.

19 A operacionalização do acompanhamento das condicionalidades de saúde está prevista na Portaria Interministerial MDS/MS n. ${ }^{\circ} 2.509$, de 18 de novembro de 2004.

Revista Brasileira de Monitoramento e Avaliação | Número 6 | Julho-Dezembro de 2013 
Os sistemas de informação aqui abordados atuam de forma interdependente em resposta ao desafio do acompanhamento das condicionalidades do Programa Bolsa Família. Neste contexto, os sistemas Sicon/ MDS, Sistema Presença/MEC e Sistema de Gestão do PBF na Saúde/MS constituem-se no principal ferramental de uma complexa rede intersetorial e federativa que monitora e avalia, regularmente, a oferta e o acesso aos serviços de Educação e Saúde de cerca de 14 milhões de famílias beneficiárias do Programa. Por isso, os Sistemas de informação das condicionalidades do Programa Bolsa Família estão em constante aperfeiçoamento e desenvolvimento, apresentando novas funcionalidades que apoiam a gestão de condicionalidades nas três esferas de governo.

O acompanhamento das condicionalidades do PBF constitui uma complexa relação federativa e intersetorial, envolvendo as áreas de Assistência Social, Educação e Saúde. O sucesso da gestão dessa operação, que alcança a maioria do público no perfil saúde e educação,edeve-se a vários fatores, en- tre os quais se destacam: I) a versatilidade do Sicon, do Sistema Bolsa Família na Saúde e do Sistema Presença em se adaptar às diversas realidades dos municípios e às demandas dos usuários; II) a operação de acompanhamento estruturada a partir da rede de serviços já existentes em cada área, aas quais os Sistemas se ajustaram, valendo-se dos processos de execução das políticas setoriais e contribuindo para maior avanço e efetividade delas; III) à constituição do público a ser acompanhado, tendo por base uma única fonte de dados, o Cadastro Único para Programas Sociais, embasado por uma sólida rede de cadastramento e atualização regular.

A riqueza das informações coletadas e consolidadas por meio dos Sistemas, além de possibilitar o acompanhamento do cumprimento das condicionalidades, ensejm a atuação das políticas públicas para a superação das vulnerabilidades sociais identificadas. Isso é possível graças a uma ampla rede de atuação intersetorial e às informações refinadas e confiáveis, obtidas tempestivament, por meio dos sistemas. 


\section{Referências bibliográficas}

CUNHA, i. Transferência de Renda com Condicionalidades: a experiência do Programa Bolsa Família. In: Concepção e Gestão da Proteção Social Não Contributiva no Brasil. Brasília: Ministério do Desenvolvimento Social e Combate à Fome, Unesco, p.331-361, 2009,

SENNA, M. de Co a. et al. Programa Bolsa Família: nova institucionalidade no campo da política social brasileira? Rev. Katál, Florianópolis, v.10, n. 1, p. 86-9, 2007. 